See Article page 40 in the December 2020 issue.

\section{Commentary: Virtual thoracic endovascular aortic repair for type A aortic dissection: Engineering transforms clinical reality}

\author{
Zhongjie Wang, $\mathrm{PhD}$, Yue Xuan, $\mathrm{PhD}$, \\ Elaine E. Tseng, MD, and Liang $\mathrm{Ge}, \mathrm{PhD}$
}

Acute aortic dissection is a life-threatening medical emergency that often requires repair of dissected aorta. Thoracic endovascular aortic repair (TEVAR) has been established as the standard of care for type B aortic dissection but has limited application in type A aortic dissection, primarily due to a limited landing zone for properly implanting the stent graft for entry closure. Open-heart surgery remains the standard of care for type A aortic dissection, whereas TEVAR is emerging as an alternative strategy for patients with very high surgical risks.

The goal of TEVAR is to successfully close the entry tear to induce false lumen thrombosis and expand true lumen without forming new entry tears or causing aortic rupture. Successful TEVAR requires a proper landing zone in both distal and proximal ascending aorta without blocking coronary arteries and interfering with the aortic valve. As with any other endograft treatment, TEVAR implantation is under fluoroscopic guidance, and estimation of the proper landing zone is done visually. A crimped stent graft geometry would be fairly different from a fully expanded one, making it hard to judge whether a specific location is sufficient for proper implantation. Such a challenge is clearly demonstrated by Yuan and colleagues, ${ }^{1}$ where they showed that, despite an initial "proper" landing of stent graft (where the graft is only partially expanded), the interaction between

From the Department of Surgery, University of California San Francisco; and San Francisco Veterans Affairs Medical Centers, San Francisco, Calif.

Funded by National Institutes of Health, R01HL119857-01A1.

Disclosures: Dr Wang reported a postdoctoral fellowship grant from the American Heart Association. Drs Tseng and Ge reported R01 from the National Institutes of Health. Dr Xuan reported no conflicts of interest.

The Journal policy requires editors and reviewers to disclose conflicts of interest and to decline handling or reviewing manuscripts for which they may have a conflict of interest. The editors and reviewers of this article have no conflicts of interest.

Received for publication Oct 29, 2020; revisions received Oct 29, 2020; accepted for publication Nov 12, 2020; available ahead of print Nov 19, 2020.

Address for reprints: Liang Ge, PhD, Division of Cardiothoracic Surgery, San Francisco VA Medical Centers and University of California San Francisco, 4150 Clement St, San Francisco, CA 94121 (E-mail: liang.ge@va.gov).

JTCVS Techniques 2021;5:8-9

2666-2507

Copyright (C) 2020 The Authors. Published by Elsevier Inc. on behalf of The American Association for Thoracic Surgery. This is an open access article under the CC BY-NCND license (http://creativecommons.org/licenses/by-nc-nd/4.0/).

https://doi.org/10.1016/j.xjtc.2020.11.003

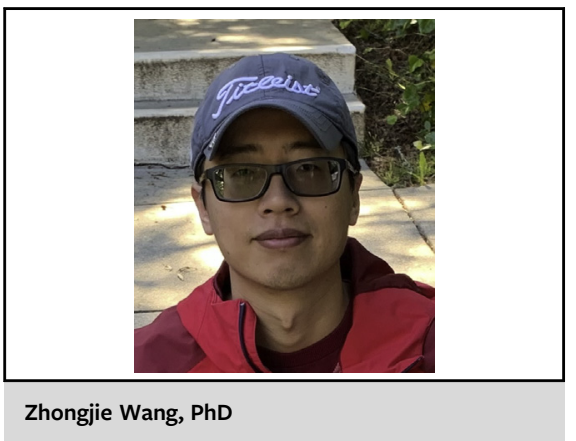

CENTRAL MESSAGE

Virtual TEVAR through finite element could potentially predict the immediate technical success or failure of TEVAR implantation on a patient-specific basis.

aortic tissue and the endograft and the further expansion of the graft could lead to migration of the graft distally, causing TEVAR failure.

This study shares similar limitations to many other patientspecific biomechanics analysis of the ascending aorta, including the lack of knowledge of zero-pressure configuration, patient-specific material property, and thickness of the aorta. These limitations make the exact wall stress values less reliable. The authors' virtual TEVAR simulation is thus not suitable for predicting the risk of aortic rupture due to TEVAR. Their study, however, focused on landing success of the endograft. The endograft is the one component with the largest amount of deformation during TEVAR and is also the one component that we can accurately measure the mechanical properties before virtual TEVAR. The uncertainties of the aortic material property would have secondary impact on the predicted outcome with regard to the final landing of endograft. Of course, validation remains the key before such a technique can be applied clinically.

The biggest technical challenge in applying a virtual TEVAR technique as conducted by Yuan and colleagues to a clinical setting is the significant processing time it takes. As indicated in their paper, it took about 30 hours to conduct one virtual TEVAR simulation, and multiple virtual simulations are necessarily to identify the better implantation option in TEVAR. For an emergency as acute aortic dissection, we simply do not have the luxury to wait for such a long planning step. Significant technical advancement to reduce the turnaround time is thus necessary before virtual TEVAR planning become reality for acute type A dissection. However, for chronical aortic 
dissection or potentially future elective endograft repair of ascending thoracic aortic aneurysm, current workflow could be feasible.

\section{Reference}

1. Yuan X, Kan X, Xu XY, Nienaber CA. Finite element modeling to predict procedural success of thoracic endovascular aortic repair in type A aortic dissection. J Thorac Cardiovasc Surg Tech. 2020;4:40-7. 